\title{
The Impact of Digital Economy on Employment-Thinking Based on the Epidemic Situation in 2020
}

\author{
Xia Tian ${ }^{1, a}$, Pei Jingsong ${ }^{1, b}$ \\ ${ }^{1}$ Beijing Jiaotong University
}

\begin{abstract}
In recent years, the digital economy has achieved rapid development, especially playing an irreplaceable role in improving employment patterns, creating job opportunities, and adjusting employment structure. A sudden outbreak in 2020 impacted people's lives, and a large number of real economies faced the situation of delayed resumption of work, which caused problems such as shortage of funds, difficulty in sales, and layoffs. However, the digital economy has developed rapidly, ensuring social supply and promoting society. Consumption has played an important role. But the digital economy also inevitably brings a series of problems, which deepens the "digital divide". This article defines the digital economy, lists its most distinctive features, explains the positive impact of the digital economy and the problems it may bring, and proposes countermeasures and suggestions for this.
\end{abstract}

\section{Introduction}

Since the outbreak of the new crown epidemic, General Secretary Xi Jinping has attached great importance to it and pointed out that it is necessary to coordinate and advance all social tasks. While doing a good job in the prevention and control of the epidemic, it also plans to do a good job in the "six stability". The first job of "Six Stability" is to stabilize employment. Since the outbreak, various places have taken measures to delay the resumption of work. Although people's contact has been avoided, corporate activities have also been affected to varying degrees. However, the digital economy has performed well in this epidemic, especially online consumption, which solves the problem of people's difficulty in purchasing and consuming. It is the most active and buffering economic form in the epidemic. Especially in terms of employment, the digital economy takes advantage of its advantages to carry out online offices, which avoids the movement and contact of people to the greatest extent, plays a role as a social stabilizer, and also promotes the normal development of other industries.

\section{Definition of digital economy}

Currently, there are many different terms used to describe the new economic environment, such as the digital economy, information economy, cloud economy, and new economy. No matter what kind of new economic form is expressed, it actually has its focus, but also has common characteristics [1]. Therefore, before we start exploring the digital economy, we must first know what is the digital economy? Digital economy is a new form of economic and social development after agricultural economy and industrial economy. According to the "G20 Digital Economy Development and Cooperation Initiative" issued by the G20 Hangzhou Summit, the digital economy is a new economic form. Unlike the real economy, its most critical production factors are information and knowledge, and the most important carrier It is an information network that mainly relies on the use of information technology to efficiently complete a series of complex economic activities.

\section{Characteristics of the digital economy}

\subsection{Platform}

The digital economy enables economic activities between enterprises to be realized only by broadband connection, and most transaction activities can be carried out on online platforms. Not only that, the digital economy has also changed the form of employment. Unlike the traditional enterprise bundling employment relationship, the digital economy makes workers' working hours, work locations, and work content more flexible. People can transcend space restrictions and obtain employment opportunities from long distances. , Forming a new way of employment and entrepreneurship based on the platform.

\subsection{Non-contact}

The digital economy is such an economic form, and its social activities are based on the numbers of 0 and 1 [2], or it can be said that the digital economy is a string of codes, a group of numbers, which consists of 0 and 1[3]. In this way, people no longer have economic activities through physical connections, such as physical machines,

${ }^{a}$ E-mail address: Tianeixia0816@126.combE-mail address: jspei@bjtu.edu.cn 
physical objects, etc., but through a set of numbers based on 0 and 1 to generate non-contact virtual economic connections, such non-contact The characteristics are particularly evident in this year's outbreak. Therefore, the digital economy is based on the efficient use of digital technology as the core productivity, and the economic form characterized by the non-contact relationship between people.

\section{The impact of the digital economy on employment}

\subsection{The positive impact of the digital economy on employment}

\subsubsection{Create a large number of job opportunities}

At present, e-commerce, computer software, IT services and other industries related to the digital economy account for $30 \%$ of the top ten industries in China's largest job demand market. A large number of Internet companies use digital technology to provide new employment ideas, employment methods, and employment channels. According to estimates, Alibaba's e-commerce platform alone has created about 3083 jobs, including Taobao store owners, express delivery, customer service, after-sales and other upstream and downstream industrial chains. In 2018, the number of people employed in my country's digital economy reached 191 million, accounting for $24.6 \%$ of the total employment in that year, an increase of $11.5 \%$ year-on-year, which was significantly higher than the growth rate of the national total employment during the same period [4]. Figure 1 refers to the analysis of the National Bureau of Statistics and IDC and BCG. After an estimate of the overall scale of China's digital economy in the next 15 years, we can see that China's digital economy can reach USD 16 trillion in 2035. Figure 2 is a measure of the employment capacity of the digital economy. By 2035, the number of employed people in the digital economy in China will be 415 million.

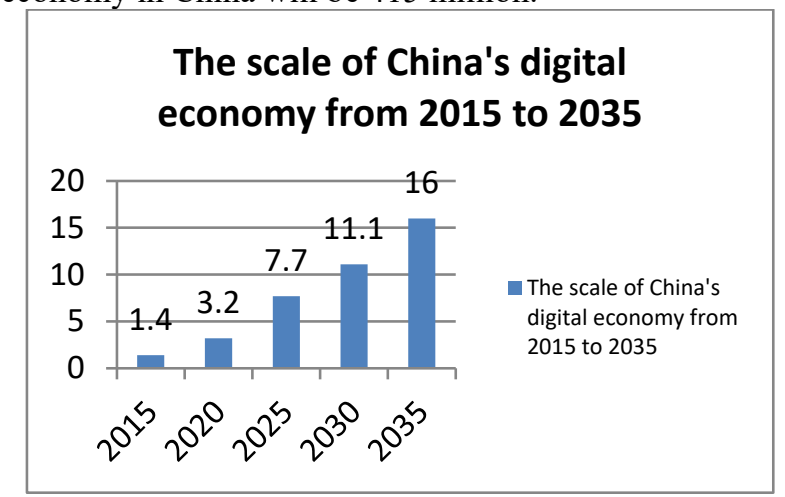

Fig1. China's overall digital economy scale calculation Source: National Bureau of Statistics; IDC; BCG analysis Note: 2015 is the estimated value, and the predicted value after 2020

\section{Employment Capacity of China's Digital Economy, 2015-2035}

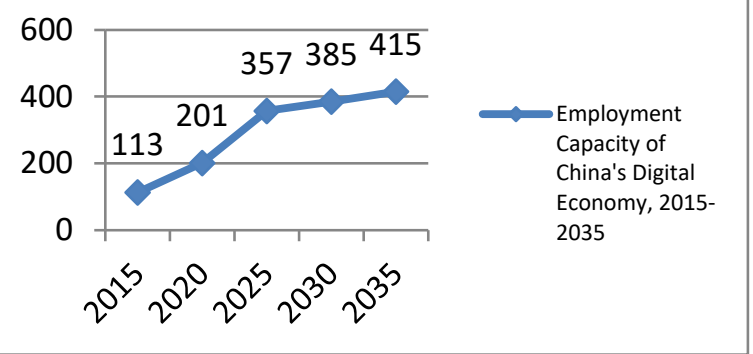

Fig2. China's digital economy scale employment capacity Note: Total digital economy scale employment capacity $=$ digital economy scale/labour force output rate

\subsubsection{Build a new type of employment ecology}

Unlike traditional labor relations with stable and close employment, the digital economy promotes a more flexible supply and demand relationship in the labor market, and makes labor selection and entrepreneurship more flexible. According to statistics, in 2018, about 760 million people in my country participated in the digital economy, and nearly 75 million people provided products and services related to the digital economy. Most of them are flexible employment [5]. It is predicted that in the next two decades, nearly half of the labor force in the country will realize self-employment and free employment through the Internet, and even worse, it may break the traditional eight-hour work system [6].

At the same time, the digital economy relies on the characteristics of digitization, platformization, and its flexibility, has made it possible for workers to start working without meeting, so that traditional employment boundaries tend to blur or even disappear. Relying on the development of digital technology, the Internet crowdsourcing platform has grown rapidly, which makes it possible for practitioners and business entities to take orders from a distance. At the same time, companies can also search for matching talents around the world. These talents can also use the Internet to achieve off-site office work, which can be part-time or full-time. Especially since this year's new outbreak of pneumonia, the digital economy has played an irreplaceable role in the "unbounded way of working". People can spend money at home without leaving home, and complete a series of methods through online grocery shopping, online lectures, online meetings, etc. Daily work and life activities.

\subsubsection{Adjustment of industrial institutions}

The digital economy has a huge role in promoting the adjustment of industrial structure. With the development of the digital economy, the proportion of the tertiary industry has gradually increased, and the scale, intensiveness, intelligence, and agricultural labor productivity of agriculture have been further improved. With the popularization of new-generation artificial intelligence technologies such as robots, more agricultural labor Will be released by agricultural automation. At the 
same time, the full penetration of computers, big data, artificial intelligence into life has promoted the development of high-end life service industries such as elderly care, tourism culture, sports health, etc., which has led to a significant increase in employment demand.

\subsubsection{Form new employment fields and drive employment}

The high-strength infrastructure since 2008 has brought high-efficiency high-speed rail and other infrastructure to our country. The convenience of transportation has accelerated the flow of products, services, and personnel, and has driven sustained economic growth. However, with the development of the digital economy, China's informatization infrastructure construction is still not perfect. Traditional infrastructure has greatly improved transportation efficiency, while the new infrastructure has played a role in improving the efficiency of informatization, making business communication more convenient and efficient. . Some people describe the role of the new infrastructure as the core driving the "troika" in the future. The main reason is that it changes the engine of the "troika" and can double the horsepower of the "troika" [7]. Therefore, with the rapid development of the digital economy, the corresponding digital infrastructure construction will also keep up. Of course, the impact of new infrastructure on employment cannot be viewed in isolation. The digital infrastructure needs more sophisticated skills with relevant expertise. Talents may drive the improvement of the quality of our labor force in the future. It is even possible to incubate many new occupations, such as the data identification industry. The programmers and engineers required for these new occupations will form a relatively stable human resource structure, which will continue to drive employment.

\subsection{A series of problems that may be caused by the digital economy}

\subsubsection{Structural unemployment will persist}

At this stage, with the continuous popularization of ecommerce, offline transactions are converted to online platforms, and a large number of physical stores are closed, causing a large number of physical store employees to lose their jobs; the rapid development of online car rental and shared bicycles has impacted the business of taxi drivers; machines And the application of artificial intelligence has caused a large number of labor-intensive enterprise workers to lose their jobs; the rise of digital media has forced traditional media personnel to change jobs, start businesses, and so on. According to the 2016 Global Human Capital Report, 7 million jobs will disappear from the planet in 2020, including basic white-collar workers and blue-collar workers. This number will continue to increase with the improvement of automation and the development of artificial intelligence [8]. Therefore, as long as the science and technology is in the process of continuous development, the economic structure will change and adjust accordingly, then structural unemployment will continue to exist, and even become a social norm.

\subsubsection{The digital divide continues to expand}

Under the wave of digital economy, workers in different fields need to have certain digital literacy in order to better follow the digital trend and complete their work efficiently. This is already a basic right of people. However, in rural areas and remote mountainous areas where information is blocked and underdeveloped, many people still have no access to mobile phones and computers and cannot enjoy this right. In different regions and between different groups of people, due to different education levels, different economic conditions, and different external environments, there are still "knowledge gaps" and "information gaps" that are difficult to bridge. According to statistics, at the network access level, as of May 2020, over $70 \%$ of the world's geographic space involved 3 billion people without Internet access [9]; at the digital literacy level, according to EU statistics, $47 \%$ of the EU's population has no corresponding counterparts "Digital capabilities" [10]; as of March 2020, the number of Chinese netizens reached 904 million, the Internet penetration rate reached $64.5 \%$ [11], and more than $90 \%$ of poor villages in 2020 achieved broadband network coverage [12], but the current "knowledge gap" and "information The "divide" still has a tendency to expand, especially between urban and rural areas, and between the east and the west.

\subsubsection{Management system mechanism lags behind}

At present, a variety of flexible employment models and a large number of freelancers have emerged in the digital economy, but problems have also arisen. It is difficult to adapt to the employment statistics system, labor security system, and employment support policies under the traditional economic pattern. The incomplete statistical system, the need to improve legal policies, and the backward management mechanism make the contribution of the digital economy to economic growth difficult to assess and underestimate the contribution to employment.

\section{Policy recommendations}

At present, although the new crown epidemic in my country is under certain control, the global situation is still not optimistic. Therefore, strict prevention and control to prevent the spread of the disease is still an important process. Therefore, the main prevention and control methods in the future should still minimize the actual contact between people. In this context, how to reduce the cost of epidemic prevention and promote sustained economic growth is not only a short-term response policy, but also a long-term strategy to maintain sustained economic growth and prevent social disease risks.

\subsection{Improve policies and regulations}

It is necessary to gradually adapt to the development laws 
of the digital economy, optimize and adjust the content of labor relations laws and policies, and gradually include contract signing, salary payment, social insurance premium payment, and work injury treatment into the scope of legal protection, and protect the legal rights and interests of workers in the digital economy to the greatest extent possible. In order to better meet the needs of flexible employment in the digital economy, we must actively explore innovative forms of social security, further lower the threshold, implement precision services, and update the legal policies, standards, and years of social security payment in a timely manner.

\subsection{Improve the statistical monitoring system}

It is necessary to improve the existing taxation and social security policies to make them more suitable for flexible employment. Explore the implementation of hourly social insurance payment methods to ensure that taxpayers can pay taxes in a timely manner. Vigorously adjust fiscal and taxation policies, standardize product and service transactions, and effectively protect the legitimate rights and interests of both parties. Accelerate the establishment and improvement of the statistical system related to the digital economy, include the employment of the digital economy in the scope of statistics, further improve the statistical caliber and survey methods, accurately, comprehensively and objectively reflect the social reality, and do not ignore or omit the driving force of the digital economy for employment and entrepreneurship The government must play a role in guiding the healthy development of the digital economy.

\subsection{Improve crowd digital skills}

For the current job seekers, it is necessary to increase the cooperation between schools and enterprises, and carry out practical training bases on big data, cloud computing, artificial intelligence, so that job seekers can truly feel and learn the development speed of the digital economy, and reserve for the future development of the digital economy. Talent. For social workers, it is necessary to vigorously implement the digital skills retraining project for workers in traditional industries. To deal with the unemployment or reemployment of traditional industries in the development of the digital economy, the government or enterprises must carry out the necessary digital skills training to provide new skills for the unemployed. Employment ideas and employment methods. For some special groups, such as the urban unemployed, rural labor, vulnerable groups, etc., strengthen targeted digital skills training. Innovate vocational training and subsidies for digital skills, adapt to market needs and implement orderbased training to better meet the needs of the development of the digital economy and the needs of employees to upgrade their digital skills [13].

\subsection{Seize the opportunity of new infrastructure and make up for the labor gap}

According to estimates, by the end of 2020, the shortage of new infrastructure talents, such as algorithm engineers, database development engineers, and system architects, will reach 4.17 million. Therefore, on the one hand, it is necessary to vigorously carry out school-enterprise cooperation, continuously expand "water sources" in colleges and universities, and provide intellectual support for industrial needs. Make up for this huge talent gap, thereby driving employment [14].

\section{Conclusion}

In this new crown epidemic, a number of digital economic technologies have played a role in the prevention and control of the epidemic. Therefore, China should take the important role of the digital economy in the epidemic as a market opportunity, and take the society's urgent need for the digital economy as a driving force for consumption. Great investment in technological innovation of the digital economy, thereby promoting the upgrading of the entire digital economy. In the future of the digital economy, the unknown is far greater than the known. We are fortunate to have experienced and witnessed a great digital revolution, and fortunate to create and write a great digital age.

\section{Acknowledgments}

Here I want to solemnly thank my mentors and classmates. With their help and review, I was able to successfully complete this paper. I also want to thank many seniors for their research in the digital economy. Work, with accumulation and precipitation, I can stand on the shoulders of giants and continue to study deeply, thanks again.

\section{References}

1. Zhang Qinglong. What does the digital economy and new infrastructure mean to enterprises? [N]. China Accounting News, 2020-06-05(011).

2. Zhao Yupeng, Wang Zhiyuan. A Brief Discussion on Digital Economy and Digital Economy Era [J]. Journal of Guangxi University for Nationalities (Philosophy and Social Sciences Edition), 2003 (S1): 113-114.

3. Ma Yan, Li Yun, Cai Minqiang. Political Economics Explanation of "Internet Space" [J]. Academic Monthly, 2016, 48(11): 70-83.

4. China Information and Communication Research Institute. White Paper on China's Digital Economy Development and Employment (2019) [EB/OL].

5. National Information Center. Annual report on the development of China's sharing economy (2018) [R/OL].

6. Ali Research Institute. Digital Economy 2.0 Report [R/OL].

7. Jiang Qiping. How to view the role of the new infrastructure in driving the economy $[\mathrm{J}]$. Internet Weekly, 2020(11): 70-71. 
8. Song Xiaoling. An empirical test of digital inclusive finance narrowing the urban-rural income gap $[\mathrm{J}]$. Finance and Economics, 2017(06): 14-25.

9. New Infrastructure" China Satellite Internet Industry Development Research White Paper.

10. Liu Yijun. The digital economy can bring a new blue ocean, and it will also bring about "new illiteracy" [EB/OL].

11. The 45th Statistical Report on Internet Development in China in 2020-Netizen Attributes. CNNIC

12. Central Cyber Office, National Development and Reform Commission, Poverty Alleviation Office of the State Council. Online Poverty Alleviation Action Plan [EB/OL].

13. Yang Peiqing, Zhang Hong. Develop digital economy, promote employment improvement [J]. New West, 2019(16): 80-83.

14. Sun Dawei. The new infrastructure should be "hard" and "soft" [N]. Liaoning Daily, 2020-06-05(001). 